\title{
Cuerpo, arte y escuela. El lugar del desnudo femenino en los libros de texto de ciencias sociales
}

\author{
Body art school. The place of the female nude in textbooks of \\ social sciences
}

VICENTE PÉREZ-GUERRERO*

\begin{abstract}
Resumen: En este trabajo nos preguntamos por cómo la enseñanza escolar del "desnudo femenino", en el área de conocimiento de la ESO (Educación Obligatoria Secundaria), pudiera influir en la idea que los alumnos se forjan del cuerpo, de sí mismo y el de los otros. Tanto si tenemos presente que la identidad de género es siempre una identidad corporal, como que la identidad del desnudo en el Arte se asocia a la mujer, procede interrogarse por cómo se trata el desnudo femenino en los libros de texto.

Palabras claves: Género, cuerpo, historia del arte, enseñanza, libros de texto.
\end{abstract}

\begin{abstract}
In this essay we wonder how teaching the female nude at school, in the field of knowledge of ESO (Compulsory Secondary Education), could have an effect on the idea students make of their own body, themselves and others'. Whether we bear in mind that gender identity always refers to bodily identity or that the identity of the nude in Art is associated to women, attention must be given to how female nude is dealt with in textbooks.
\end{abstract}

Keywords: Gender, body, art history, teaching, textbooks.

\section{El estudio del cuerpo como asignatura pendiente de la escuela}

Cierto es que no hay una relación uno a uno entre la enseñanza del desnudo y lo que los alumnos piensan del cuerpo, como no la hay entre educación y construcción de identidades ${ }^{1}$. Pero, aceptando la posibilidad de que la escuela contribuya de alguna forma a la formación de personas, asumiendo también, entonces, que es la formación de ciudadanía democrática la función más importante que la Enseñanza Secundaria Obligatoria (ESO) tiene por ley

Fecha de recepción: 07/06/2016. Fecha de aceptación: 27/07/2016.

* Facultad de Ciencias de la Educación. Universidad de Sevilla. Profesor Asociado: vperez9@us.es Líneas de investigación: Examen escolar, la práctica escolar, memoria e historia. Pérez-Guerrero, V.M. (2015): Del examen a la evaluación pasando por el paradigma del emprendedor. Evaluar: ¿para qué?, ¿para quiénes?, Conciencia social, 19, pp. 145-152. Mateos Montero, J. y Pérez-Guerrero, V.M. (2011): Pensando sobre la obra de Carlos Lerena, Con-ciencia social, 15, pp. 61-106.

1 Según Martín Criado (2010) habría, de hecho, que replantearse las funciones que habitualmente se atribuyen a la escuela, empezando por derribar la fe en la premisa de que el individuo actúa, fundamentalmente, en función de los valores interiorizados en sus años de escolarización. 
encomendada, es posible propiciar un debate social, y no sólo académico, sobre qué y cómo debiera enseñarse. $\mathrm{O}$, al menos, en relación al contenido de los manuales, los profesores podrían tener entre sus deberes evaluar críticamente qué clase de subjetividades se representan en estos materiales y qué efectos podría tener entre el alumnado ${ }^{2}$. Lo cierto es que, con relación al cuerpo, por ignorancia o una falsa neutralidad ideológica, si los libros escolares de Historia del Arte no cuentan cómo cada época histórica es encarnada en un "régimen corporal" concreto, tampoco parece que el profesorado, que es quien decide el uso que se le da al texto, haya recibido formación académica a este respecto. En todo caso, el conocimiento de la construcción social del cuerpo, no sólo del género (Scott, 1990), pudiera ser de gran utilidad para abordar el que, sin duda, es uno de los principales problemas con el que los jóvenes se enfrentan en la actualidad. Por consiguiente, desde la toma de conciencia de la "obsesión" por el cuerpo, sería posible pensar en la utilidad de la enseñanza de las ciencias sociales y la historia en la ESO para mostrar cómo el poder se ejerce sobre la anatomía y, en efecto, produce una determinada ética y estética. En este sentido, si pensar históricamente puede ayudarnos a dilucidar su papel como objeto político, su abordaje desde la escuela se podría entender como respuesta a una demanda social. De esta manera, el aula sería un lugar desde el que poder formular planteamientos de resistencia a los manejos mercantiles del consumo de modas, así como un espacio de confrontación de identidades donde el profesor, ayudándose de la historia responde a las cuestiones de sus alumnos sobre el pasado, pero deja abierta la pregunta al cuestionamiento del presente, a fin de qué estos pudieran construir más autónomamente su propia imagen corporal. Se trata de intentar, en suma, que aquello que se enseña pueda ser aplicado a otros contextos y situaciones de la vida ${ }^{3}$. Un planteamiento didáctico coherente, por más ideal que resulte, con ese mandato legislativo de formar ciudadanos críticos.

El libro de texto como condicionante del cuerpo escolar

Antes que otra cosa habría que recordar la importancia cada vez mayor que tiene la investigación de la manualística escolar como un campo disciplinario propio. Un sector de investigación que, según Escolano (2006), sirve para entender tanto "el curriculum de la educación institucionalizada" como "la cultura de oficio de los enseñantes". Es gracias a esta disciplina por lo que sabemos que, siendo utilizado como principal recurso en el aula por más de un $90 \%$ del profesorado, el libro de texto constituye la fuente de conocimiento básica para el alumnado. Tiene una importancia pedagógica tan fundamental que, en muchas ocasiones, los propios profesores llegan a confundir las propuestas curriculares de las editoriales con el curriculum oficial y prescrito. Ahora bien, para no llevarnos a engaño respecto a la trascendencia ideológica de los textos es necesario conocer el valor de uso que los

2 Algo que, por lo demás, se prescribe en la normativa vigente. La ley Orgánica 3/2007, de 22 de marzo, para la igualdad efectiva de mujeres y hombres, establece en su artículo 24 que las Administraciones educativas, en el ámbito de sus respectivas competencias, desarrollarán, con tal finalidad, las siguientes actuaciones: b) La eliminación y el rechazo de los comportamientos y contenidos sexistas y estereotipos que supongan discriminación entre mujeres y hombres, con especial consideración a ello en los libros de texto y materiales educativos.

3 Dificultad que, desde una perspectiva reproduccionista simple, se debe a la creencia de que los contenidos enseñados no suelen responder más que a una intencionalidad académica. Mientras que desde el planteo de Lave (1991) y la corriente teórica de la cognición en la práctica resulta irresoluble, por la imposibilidad, según dicen sus defensores, de reproducir en el aula el modo en que los sujetos hacemos frente a los problemas de la vida en la calle. 
profesores hacen de ellos. Lo cual, por otra parte, implicaría un cierto desvelamiento de las creencias y costumbres del profesorado, el estudio, en definitiva, del habitus del profesor ${ }^{4}$. A este respecto, hemos de ser cautelosos y evitar caer rendidos al idealismo pedagógico, según el cual el profesor dispone del libro a su antojo. O sólo condicionado por sus concepciones acerca de qué enseñar. Es frecuente en educación presuponer que los profesores actúan en el aula conforme a sus creencias. La realidad es que, sustancialmente hablando, los profesores que enseñan sin libro de texto no hacen cosas muy diferentes al resto, pues hasta las prácticas de los docentes más innovadores están siempre enmarcadas en unas férreas constricciones. Unas relativas al espacio, como la disposición y forma del aula; y otras a la gestión del tiempo, o a la misma asignación y separación de horarios por materias de conocimiento. Nos encontramos así con unas disposiciones crono-espaciales difícilmente controlables. Pero es que, además, la institución escolar impone otras dos obligaciones. En primer lugar, la necesidad de producir un conocimiento escolar susceptible de someterse a una lógica examinatoria, que, según Merchán (2005), exige memorización más que el desarrollo de un pensamiento elaborado; y, en segundo lugar, pero igual de importante, la producción del gobierno del aula. Gobernar es, en este sentido, lograr el orden escolar deseado. Algo que sólo es posible teniendo a los alumnos ocupados, con o sin libro de texto. Otra cosa es que, en efecto, el manual responde a la perfección a esta necesidad de enseñar las mismas cosas "a todos y a cada uno" (omnes et singulation) a un tiempo, de forma que, en todo momento, el profesor puede saber qué debieran estar haciendo todos. Abundando en esta consideración, por más que se oiga decir que el cuerpo es, junto con las emociones, el gran olvidado de nuestro sistema educativo, la verdad es que la escuela aplica un trabajo no siempre consciente, pero continuo y constante con y en los cuerpos de los alumnos. De hecho, antes que al logro de otros fines pedagógicos asumidos oficialmente como más valiosos, enseñar supone conseguir "cuerpos dóciles" (dócil del latín docilis, que significa "enseñable"), puesto que esta enseñanza es la base y la condición de los demás aprendizajes. Esto explicaría la importancia que, al objeto de producir disciplinados discípulos, los docentes dan a los juicios y sanciones relacionadas con el tiempo (impuntualidad, absentismo), el orden (interrupciones de trabajos) y el control corporal (actitudes "incorrectas" y gestos "inapropiados"). Ahora bien, el reconocimiento de esta necesidad no implica que el profesorado sea consciente del papel que la escuela cumple en la constitución de sujetos-cuerpos. En consecuencia, el control del cuerpo se da como requisito imprescindible para la práctica de la docencia, pero no hay conciencia de cómo la escuela, por medio del juicio normalizador y la inculcación de convenciones culturales dominantes, se incardina en los cuerpos de los escolares. Esto principalmente se debe a que, más allá de las etapas de educación infantil y primaria, el cuerpo no es considerado una categoría central del proceso de enseñanzaaprendizaje. De forma que el proceso de corporización, entendido como el resultado de un proceso pedagógico-social e históricamente producido, queda absolutamente ignorado por el código profesional del profesorado de secundaria. "Prueba de ello es que -dice J. Varela (1991, 246-247)- a medida que se avanza en la carrera escolar el juego, el movimiento, en

4 A la manera en que lo hace Apple (1996), se podría considerar el libro de texto como un contexto dentro del cual puede describirse una jerarquía estratificada de estructuras significativas o, si se prefiere, como eslabón de una cadena de problemas subsidiarios. 
suma, lo considerado corporal, tiende a verse progresivamente relegado en provecho del saber intelectual en torno al cual gira el éxito o el fracaso escolar y, en gran medida, el éxito o fracaso personal". Luego, se explicaría así el uso generalizado de esta tríada pedagógica "mesa, libro y cuaderno", pero, con relación al cuerpo, lo relevante serían los efectos de esta pedagogía silenciosa cuya valía se mide por su capacidad de disponer a los alumnos en sus pupitres, impelidos a estar sin poder moverse por la obligación de realizar las tareas del libro. Por consiguiente, cada uno en su sitio y el libro en el de todos. De esta forma, el alumno va adquiriendo una forma de ser, e incorporando a la vida social la disposición del cuerpo que el orden escolar establece como la manera correcta de saber estar (Foucault, 1996; Milstein y Mendes, 1999; Pérez-Guerrero, 2005).

\section{La existencia, o inexistencia, del desnudo femenino como condicionante de los libros de texto}

Como íbamos diciendo, ya sea por el conservadurismo ideológico de las administraciones, porque los profesores no lo demandan o como consecuencia de las reediciones que practican las editoriales, si algo caracteriza a la manualística escolar es su renuencia a adoptar nuevos contenidos y enfoques. Lo cierto es que nada del conocimiento que la teoría social del cuerpo ha aportado sobre la diversidad de itinerarios e historias corporales, o sobre la construcción cultural de los géneros, encontraremos en estos materiales didácticos. Dicho esto, en lo que concierne al desnudo en la Historia del Arte, lo primero sería constatar cuáles son las representaciones que, entendidas como más valiosas, se seleccionan para ser transmitidas a los alumnos ${ }^{5}$. ¿Por qué esas y no otras? A su vez, debiera tenerse presente que la forma en que se organizan los contenidos escolares, dentro de cada tema o lección, sigue la lógica interna propia de la disciplina. Muy brevemente, se puede decir que la organización de los contenidos artísticos -en la asignatura "ciencias sociales, historia" (ESO)- se dispone en una secuencia cronológica lineal, del pasado al presente, basada en el arbitrario cultural propio de la historiografía decimonónica de las edades: antigua, medieval, moderna y contemporánea. De hecho, cualquiera que examine un manual de historia escolar comprobará que lo histórico, así entendido, comparece como una sucesión de acontecimientos y no como una explicación relevante de lo social. Es decir, el pasado sigue presentándosenos en los manuales escolares de hoy tal y como se hacía en el siglo XIX, es decir, como una crónica de reyes o de Estados en la que apenas si tiene cabida eso que se ha dado en llamar historia de la vida cotidiana, o, con más acierto, historia social, y en la que tendría sentido la dimensión histórica del cuerpo ${ }^{6}$. Por

5 Al margen de la asignatura de Historia del Arte que actualmente se imparte en $2^{\circ}$ Bachillerato, según la normativa LOE (2006), en la enseñanza obligatoria sólo se estudia arte en $1^{\circ}$ y $2^{\circ}$ ESO en la asignatura de Ciencias Sociales, Geografía e Historia, y luego en $4^{\circ}$ ESO, en la materia de Ciencias Sociales, Historia.

6 La historia es, por definición -tal y como gustaba recordar L. Febvre-, absolutamente social. Por tanto, este tipo de demarcaciones sólo se entiende como reacción al dominio de la historia política, entendida ésta como aquella que privilegia a las instituciones y a los sujetos de poder y la guerra. Por su parte, el interés históricoantropológico del cuerpo se remonta a la seminal conferencia de M. Mauss Técnicas y movimientos corporales de 1934. Y, si bien se ha mantenido como un lugar de intersecciones en el que siguen confluyendo otras disciplinas ocupadas de lo social, la conceptualización del cuerpo como objeto de estudio de la historia se remonta a la década de 1970. En este sentido, debe destacarse la importante influencia que la obra El proceso de civilización 
lo demás, resulta significativo que las editoriales atentas a las nuevas tendencias historiográficas y pedagógicas hayan ido incorporando unos apartados fijos en sus programaciones didácticas, del tipo: "Para saber más" o "Investiga en internet", en los que, ciertamente, se proponen actividades relacionadas con la vida cotidiana de la mayoría de la población. Por ejemplo, el estudio de cómo se vestía la gente en diferentes épocas históricas, cómo era la familia o la alimentación. Sin embargo, es fácil comprobar que están pensados como recursos didácticos complementarios del discurso teórico principal. Así, a modo de documento anexo, bien al final de la lección o en los márgenes del texto central, se presentan como algo subsidiario que, sobre todo, sirve de pausa y/o desahogo del trabajo entendido como fundamental. Sin llevar a engaño, puede decirse que las editoriales siguen planteando la Historia "de siempre" como lo realmente importante, mientras que la "historia social" se sigue considerando como curiosidad histórica y, en consecuencia, como un contenido adicional. Si a esto, además, le sumamos un denodado afán por evitar los temas que puedan resultar conflictivos, se entiende que los editores no puedan, en efecto, sustraerse a ilustrar los textos con desnudos femeninos, pero siempre con aquellos que han acabado siendo asumidos como reverenciales en la Historia del Arte occidental, y, ante todo, se desentiendan de sus razones, pues éstas, qué duda cabe, pudieran suscitar dudas y hasta quejas. Ahora bien, en tanto en cuanto el desnudo femenino forma y juzga el cuerpo de la mujer, resulta evidente que no se trata de una decisión inocua, tiene efectos, sin duda; $\mathrm{y}$, en consecuencia, debiera ser objeto de debate.

\section{La importancia de la enseñanza del desnudo femenino en la ESO}

Sea como fuese, lo relevante es que esta pedagogía silenciosa e invisible, tanto como la falsa equidistancia ideológica de los libros de texto, está coadyuvando a la forja de un tipo de subjetividad. Incluso puede que, al enseñar el desnudo femenino sin significados sociales y culturales, se esté dando por supuesto que la anatomía es, más que un hecho político y social, un destino inevitable. Basta tomar como ejemplo las ilustraciones que aparecen en el manual de $4^{\circ}$ ESO de la Editorial Vicens-Vives de García Sebastián y Gatell Arimont (2008). Editorial que no sólo es la más usada entre el profesorado que imparte la asignatura de "Sociales, Geografía e Historia" para la Educación Secundaria Obligatoria, sino que pasa también por ser la más progresista de las editoriales mayoritarias (Atienza Cerezo y Van Dijk, 2010)7. Siendo significativo que los desnudos seleccionados sean los

del sociólogo alemán N. Elias ha tenido sobre los historiadores profesionales, así como los trabajos del filósofo M. Foucault. Desde entonces el interés no ha dejado de aumentar, los también franceses Alain Corbin y Georges Vigarello dirigieron una historia del cuerpo en tres volúmenes (Seuil), dos de los cuales aparecieron en 2005, y un tercero en 2006. Puede citarse también el trabajo de Le Goff y Truong sobre el cuerpo en la Edad Media, así como el Dictionnaire du corps dirigido por Bernard Andrieu y Gilles Boëtsch (2008).

7 Cuesta, R. (2007) señala que, en los últimos 25 años, han desaparecido la mitad de las empresas editoriales. Para el caso de Ciencias Sociales, cinco editoriales entre la que destaca Vicens Vives, se reparten el $75 \%$ de la cuota de mercado. Actualmente, según http://www.vocesdepradillo.org/content/el-maloliente-negocio-delos-libros-de-texto (12/05/2015), el primer grupo empresarial en volumen de negocio lo constituye la Iglesia Católica, propietaria -total o parcial- de las siguientes editoriales: Grupo SM (fundada por los Marianistas), Edebé (fundada por la congregación Salesiana), Edelvives (pertenece a los Hermanos Maristas) y Bruño (fundada por el Instituto de los Hermanos de las Escuelas Cristianas La Salle). Los otros dos grupos empresariales 
mismos (La Venus del espejo de Velázquez, La maja desnuda de Goya, L'Olympia de Manet o Las señoritas de Avignon de Picasso) que se reproducen en otras editoriales ${ }^{8}$, lo sustantivo es que en ninguno se dé una explicación contextual y obvien el relato de cómo el cuerpo femenino se transformó en "el desnudo". En definitiva, a efectos educativos sorprende el silencio en torno la actuación del poder sobre el cuerpo. Ciertamente, la tradición occidental del desnudo femenino que arranca en la época clásica y es continuada en la estética moderna hasta convertirse en emblema de valores e ideas universales, encaja a la perfección con la idea del saber escolar socialmente legitimado como más prestigioso. En consecuencia, siguiendo el canon clásico occidental, se tiende a naturalizar la identificación entre "el desnudo" en el Arte con el desnudo femenino. Empero, el curriculum es un producto histórico que debería someterse a un debate tanto técnico como público, puesto que la selección de unos u otros contenidos conlleva en sí mismo unas opciones de valor que condiciona el tipo de ciudadanía que la escuela forja (Pereyra, 2002). Y, desde este punto de vista, en torno al desnudo femenino podría plantearse el debate acerca de su condición política y no sólo por una cuestión de género. El arte mismo es político y produce efectos ideológicos, tanto en el punto de su producción como en el de la recepción. Por consiguiente, si estamos del lado de una educación para todos y todas, hemos de interrogarnos por la ideología que estos artefactos portan. Pertinente es también preguntarse por la identidad sexual del artista creador. Del desnudo femenino practicado por mujeres artistas no hablamos porque para ellas era impensable. Pero sí se podría plantear la posibilidad de incluir en los libros de texto los desnudos masculinos que practicaron algunos artistas como, verbi gratia, Gustave Caillebotte. Asimismo, habría de considerarse cómo afecta el desnudo femenino al receptor que, en este caso, es tanto hombre como mujer. Y, a mayor abundancia, asumir que sobre la mujer estas imágenes suponen una doble condición, por ser, a la vez, el papel del objeto visto y del sujeto que ve. De esta forma, en posición de espectadora, la mujer forma y juzga su propia imagen contrastándola con ideales culturales. En primer lugar, el modo que el canon occidental de la Historia del arte establece como "condición femenina", es decir, a posar como un objeto. Esto, sin duda, tiende a configurar a la mujer como individuo erótico, dependiente o subordinado, y su recepción, inevitablemente, ejerce una enorme autorregulación. Reproducimos, a continuación, como botón de muestra, una actividad típica de un libro de texto tipo (García Sebastián y Gatell Arimont, 2008).

controlan el 50\% del mercado editorial del libro de texto por medio de Anaya y Santillana. El grupo Hachette es propietaria del Grupo Anaya que incluye a Algaida, Vox, Cátedra, Pirámide o Alianza, mientras que el Grupo PRISA, dueño de Santillana, vendió recientemente un 25\% de su capital al fondo de inversión estadounidense Liberty.

8 En el caso concreto del texto que nos ocupa los desnudos seleccionados son La maja desnuda, entre 1790 y 1800, de Goya, página 128; El taller de pintura, 1855, de Courbet, página 133; y, El almuerzo campestre, 1863, de Manet, página 138. Pero, asimismo, se han tenido en cuenta las siguientes referencias Ciencias Sociales. Historia. Segundo ciclo. Manuel Días Rubiano, $\mathrm{M}^{\mathrm{a}}$ Isabel Fernández, Manuel Adolfo Jiménez. Editorial Oxford, 1998. Historia. $4^{\circ}$ ESO. Editorial Oxford, 2003. Historia. $4^{\circ}$ ESO. Editorial Oxford, 2008. Ciencias Sociales. Historia. Segundo ciclo. Editorial Marfil, 1999. Historia. Editorial Vicens Vives $4^{\circ}$ ESO. 2005. Historia. Editorial Anaya, 2006. Historia. Editorial Ecir, 2003. 


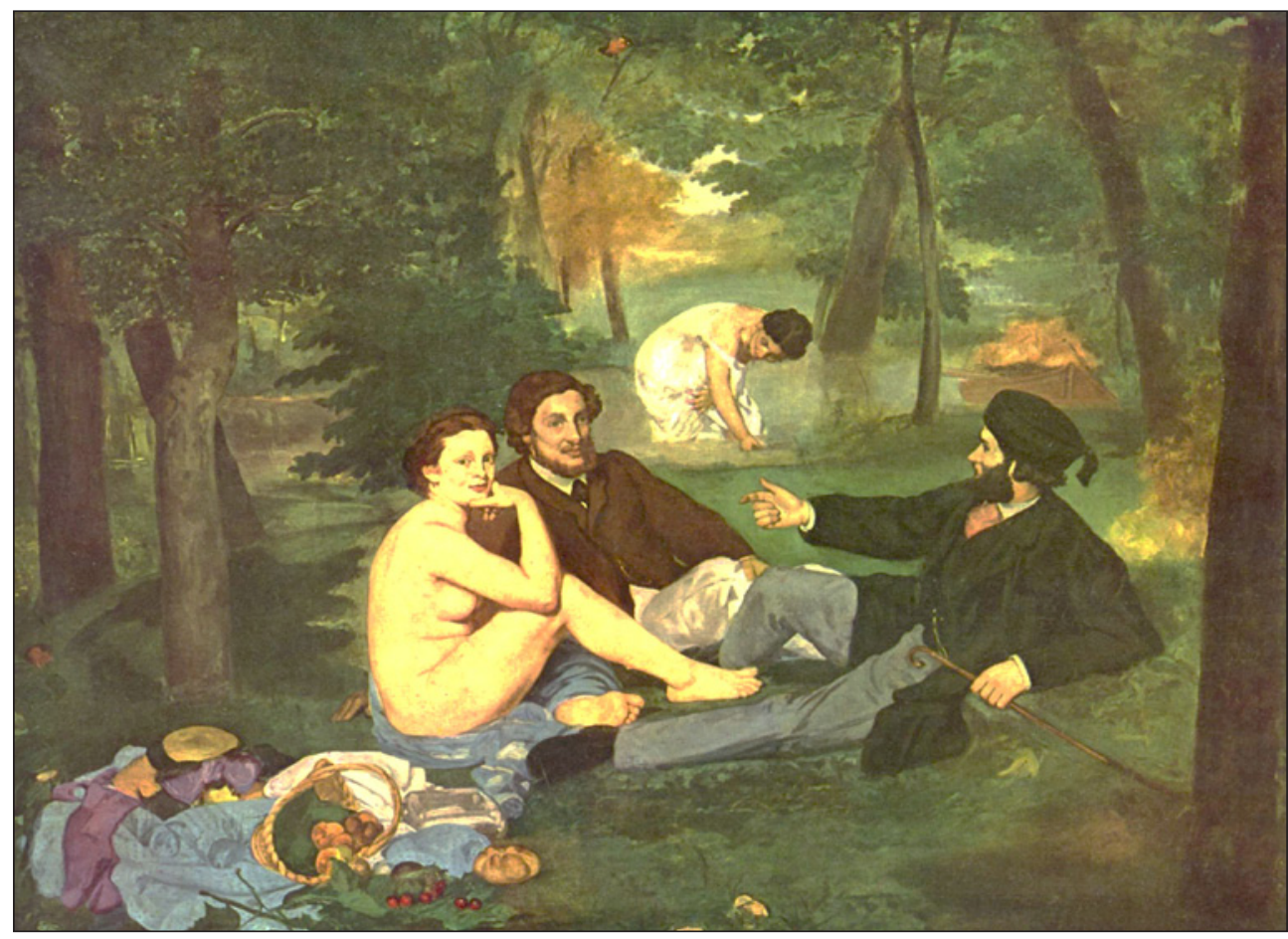

Éduard MANET: El almuerzo campestre, 1863. Este lienzo, por su tema, su composición, su forma de utilizar la pintura y su tratamiento de la luz es una revolución en el mundo del arte del siglo XIX.

1. Describe la escena que representa este cuadro. ¿Crees que los cuatro personajes se comunican entre ellos?

2. ¿Por qué crees que esta obra provocó un gran revuelo en su época?

Hay que saber que la imagen aparece descontextualizada del lugar social que ocupaba la mujer a finales del siglo XIX, sin más información que la del propio cuestionario que la acompaña. En todo caso, lo que nosotros proponemos es una didáctica del arte lo suficientemente abierta y flexible como para no quedar prisionera del punto de vista único. Una didáctica ecléctica, entendida como conjunto de miradas en beneficio de una pluralidad de perspectivas, coexistentes y, a veces, rivales en la Historia del Arte, pero, en suma, crítica y volcada sobre el estudio de problemas relevantes (Calaf, et al, 2000; Ávila, 2001; Hidalgo, et al, 2003; Cuesta, 1997, 1999)9:

9 Desde Fedicaria, Federación Icaria, plataforma de pensamiento crítico que, con pluralidad de enfoques, desarrolla sus análisis e investigaciones acerca del campo de la educación y de la producción cultural y, digamos que su órgano de expresión, Con-Ciencia social, propugnamos una enseñanza de las ciencias sociales que nada tiene que ver con la resurrección de la vieja historia de siempre y con la reconsagración de las vetustas disciplinas 
1. Mirada histórica: la obra de arte como prueba o testimonio de una época. El qué dice responde a cuándo.

2. Mirada sociológica: lo que el artista quiere decir viene determinado por el para qué y para quién es la obra de arte.

3. Mirada formal: trata de responder al cómo se dice.

4. Mirada iconológica: la obra de arte como signo, como concepción del mundo que hay que interpretar. Responde al porqué lo dice.

Por tanto, nuestro objetivo no es el de formar pequeños historiadores del arte. Nuestra preocupación pasa por introducir al alumnado en la interpretación de la obra de arte y, para el tema que nos ocupa, especialmente, desde la perspectiva de la crítica feminista. En este sentido, una propuesta interesante es el enfoque que propone L. Nead (1998). Esta teórica y activista, muy influenciada por la teoría de lo impuro de la antropóloga M. Douglas -después desarrollada por Julia Kristeva en sus trabajos sobre la abyección y lo que lo provoca-, plantea que existe una constante transcultural que define el cuerpo femenino como algo que carece de contención y que produce suciedad, como materia informe e indiferenciada, como algo que envuelve un riesgo y amenaza -siendo esto lo más grave- con desestabilizar el orden. Su argumento principal es que, en esta circunstancia "natural”, residiría el origen y la razón de ser del desnudo femenino, pues el arte, nos dice, se define como la conversión de la materia en forma, y, en consecuencia, el desnudo femenino haría lo propio con el cuerpo de la mujer, pues por medio de su tratamiento artístico lo natural dejaría paso al cuerpo cultural. Por tanto, la función primordial del desnudo femenino sería contener y regular el cuerpo, marcando el estilo artístico, la forma pictórica, la función de límite entre arte y obscenidad.

En resumidas cuentas, el desnudo femenino sería un producto cultural formalizado y convencionalizado, cuyo sentido sólo se comprende en el marco de la tradición occidental, cuyas convenciones y protocolos, hemos de revelar para lograr su compresión. A mayor abundancia, siendo conscientes del paralelismo intrínseco entre los condicionantes que generan los cambios estilísticos en el arte y los cambios estructurales en la civilización, el proceso por el cual el desnudo masculino fue sustituido por el femenino hasta convertirse, hacia mediados del siglo XIX, en la forma dominante del arte figurativo europeo sólo se explica relacionándolo con otro tipo de cambios que tuvieron lugar en un marco más general. Así, por ejemplo, en un contexto social fuertemente influenciado por la Revolución Industrial, el desarrollo del urbanismo y los problemas sociales en torno a la prostitución, el movimiento sufragista, o las teorías misóginas de Schopenhauer o Nietzsche -entre otros-, tuvo lugar una redefinición de la feminidad y de la sexualidad femenina que, de alguna manera, contribuyó a crear el mito de la mujer fatal fuertemente presente en la iconografía de la época. A nuestro parecer, la reconstrucción de la forma en que ese discurso sirvió al condicionamiento social de los sujetos debiera asimismo ser objeto de reflexión en el campo de la educación.

escolares. Atentos a los problemas de los hombres y mujeres de nuestro tiempo, para nosotros la enseñanza de la Historia (de la Geografía y de otras ciencias sociales) sólo adquiere sentido en relación con las preocupaciones del presente y con las necesidades de emancipación individual y colectiva, y no como mera recuperación del pasado. A tal fin, el conocimiento histórico (y todo tipo de conocimiento) ha de ponerse al servicio de un nuevo tipo de ilustración crítica de las conciencias que ayude a transformar simultáneamente la escuela y la sociedad en su conjunto. 
De otra parte, no se trata de reducir el análisis de la obra de arte a la explicación contextual, o describir una obra de desnudo exclusivamente desde una perspectiva formal, o iconográfica, ignorando las cuestiones de fondo. Bien es verdad, si la interpretación de las cuestiones implícitas sin prestar atención a las propias del estilo queda huero y pobre, lo contrario es aún peor. Evitar las implicaciones políticas y culturales que la representación del desnudo femenino soporta a nivel de legitimación ideológica y de lo que históricamente se ha entendido por ser mujer, conlleva el riesgo de refrendar lo que hemos damos en llamar "condición femenina".

\section{Breves propuestas didácticas en torno al cuerpo}

Aceptando la posibilidad de que la escuela contribuya a la construcción de una ciudadanía crítica, desde una perspectiva histórica del cuerpo podría plantearse la enseñanza del desnudo femenino de cara al "empoderamiento" de aquellos que, por ejemplo las mujeres, están en situación de subordinación o discriminación. Pero, de la misma manera que el empoderamiento social de las mujeres es y será siempre corporal o no será, sería un grave error de apreciación -y al mismo tiempo un imperdonable error estratégico- considerar a la institución escolar como espacio exclusivo o privilegiado en la transformación social. Por más que el currículo se inscribe dentro de las políticas de la cultura y de las luchas sociales por la hegemonía, o el aula y, por extensión, el centro escolar, pueda ser interpretado como un campo de lucha de concepciones y posiciones. Lo cierto es que teniendo presente la función fundamentalmente conservadora de la escuela, así como los códigos socioprofesionales que guían los usos y costumbres del profesor de secundaria, lo más probable es que este tipo de propuestas tengan poca repercusión práctica. Pero, asumiendo el fuerte peso de esta realidad, en el espacio escolar es más que posible visualizar las relaciones de poder que atraviesan las imágenes corporales y, en concreto, las representaciones femeninas que predominan en los libro de texto. Por consiguiente, desde el convencimiento de la politización del curriculum, no sólo del arte, se puedan promocionar otras visiones, contrahegemónicas. De esta forma, por ejemplo, podría considerarse, como tema digno de estudio, la reivindicación de los movimientos artísticos de contestación, los fenómenos de resistencia y aquellas corrientes de creación cultural críticas con los discursos androcéntricos y eurocéntricos. Se trataría, en definitiva, de apostar por proponer alternativas pedagógicas susceptibles de cuestionar el diseño curricular tradicional y seleccionar discursos omitidos por la tradición que regula los contenidos de las editoriales.

Otra posibilidad didáctica pudiera ser la enseñanza de la Historia sobre itinerarios corporales diferentes a los dominantes, que hagan pensar en el cuerpo como un campo de juego cuyo resultado es ciertamente previsible, pero nunca del todo determinado. Cierto es que esta propuesta tendría más posibilidades de ser desarrollada en la optativa de secundaria "Cambios sociales y nuevas relaciones de género" que en la obligatoria de "ciencias sociales, historia", pero no debiera por esto escatimarse su vinculación con la enseñanza de la Historia del Arte ${ }^{10}$. Históricamente, de hecho, lo evidente es la existencia de diversidad

10 Hay que señalar el riesgo que esta materia tiene de convertirse en una "maría" por el escaso valor que tiene por no ser evaluable. Además, en tanto que optativa la pueden impartir profesores sin formación en ciencias socia- 
de configuraciones o regímenes corporales ${ }^{11}$. En cierto modo, lo normal incluso es que los modelos se resistan y fusionen. Es el caso, por ejemplo, del canon corporal de la mujer andaluza identificado con la obra de Julio Romero de Torres (1874-1930), cuyas señas de identidad más sobresalientes, a pesar de las nuevas corrientes estéticas, siguen siendo reivindicadas. Más cercano en el tiempo, el body art ha hecho del mismo cuerpo del artista su principal razón creadora. Por supuesto, el uso del cuerpo en algunas de estas prácticas artísticas es violento y esta violencia es llevada a un límite que tiene difícil justificación en el curriculum escolar. No obstante, esta opción bien podría ser pensada como una respuesta crítica a la cultura corporal hegemónica occidental. Una cultura que, por lo demás, ha conceptualizado el sistema género de un modo en que lo físico ha terminado siendo un lugar de represión y subordinación social. Luego, en tanto en cuanto su mensaje puede ser interpretado como una respuesta a las limitaciones y jerarquizaciones que la sociedad impone al cuerpo femenino, algunas de las intervenciones artísticas que, por ejemplo, desarrollaron Gina Pane o Ana Mendieta son didácticamente muy reivindicables. Es más, las performances, a la manera de los rituales "primitivos", de Ana Mendieta suponen, además de una visión crítica con los ideales corporales de belleza occidentales, una ruptura radical con la forma canónica de mostrar del arte europeo. En este sentido, si la revolución de Manet consistió en el reconocimiento del "cuadro-objeto", en la asunción de que pintar un cuadro no es lo mismo que pintar a una mujer; en tanto que su creatividad se basa en la "manipulación" artística del propio cuerpo, el body art puede ser entendido como una contestación al "cuerpo-objeto". Se podría, incluso, plantear una cierta semejanza entre el escándalo que en su época supuso la obra de Manet, revuelo del que por cierto la actividad del libro de texto seleccionada se hace eco en el cuestionario que la acompaña ("¿Por qué crees que esta obra provocó un gran revuelo en su época?") sin que, por otra parte, en el relato del texto se explique nada; y la que supondría incluir en los manuales de secundaria imágenes de las obras de esta corriente artística. En definitiva, la marginación total del "arte de acción" en los libros de texto, entre otras razones, se entiende por el papel que estos instrumentos didácticos tienen como dispositivo de legitimación social.

Desde la perspectiva de los alumnos, habría que hacer visible que el espectador está también sujeto a su propia historia y cultura. De forma que el mensaje de toda obra de arte es históricamente distinto por el filtro cultural que el lector del momento somete a los contenidos originales. Pudiera, por tanto, resultar atractivo para los propios escolares considerar su interpretación, más que como ideas previas o erróneas, como re-creación de la obra de arte y así valorar la lectura del cuerpo desnudo de la mujer en la Historia del Arte como indisociable de la que los adolescentes, desde una determinada posición social y cultural, hacen de la experiencia de su propio cuerpo.

les, lo cual nos hace igualmente dudar de su empaque como disciplina social. http://www.juntadeandalucia.es/ averroes/convivenciaeigualdad/colecc_planigualdad/n5_cambios_soc/

11 Bien sabemos, por el contrario, que no sólo las definiciones de perfección y belleza hasta las categorías "gordo" y "delgado" aunque se crean innatas, fijas y naturales, son construidas socialmente. Las mismas normas en materia de peso y talla varían, de hecho, según culturas y países (Guillaumin, 1992). 


\section{Conclusión}

En las páginas anteriores, hemos partido de que la representación dominante del desnudo femenino es un reflejo de una realidad histórica, en cuanto que esta condiciona nuestras creencias y conductas sin que, por supuesto, esto suponga la consecuencia de un plan maquiavélico e intencionado. A su vez, hemos supuesto también que esta concepción es un factor coadyuvante en la construcción de modelos sociales. Desde estas premisas, muy modestamente hemos propuesto una enseñanza del desnudo femenino que, sin ignorar los límites que las constricciones escolares imponen a la incorporación de cualquier innovación didáctica, apuesta, en coherencia con la demanda social de una educación para la ciudadanía crítica y responsable, por una idea del cuerpo en construcción y libre de cualquier determinación corporal y/o de género.

\section{Bibliografía}

Apple, Michael. W. (1996): El conocimiento oficial. La educación democrática en una era conservadora, Barcelona, Paidós.

Atienza Cerezo, Encarna y Van Dijk, Teun. E. (2010): Identidad social e ideología en libros de texto españoles de Ciencias Sociales, Revista de educación (Madrid), n. 353, septiembre-diciembre, pp. 67-106.

Ávila, Rosa. M $M^{a}$. (2001): Historia del Arte, Enseñanza y Profesores, Sevilla, Díada.

Calaf, Roser et al. (2000): Ver y comprender el arte del siglo XX, Madrid, Síntesis.

Cuesta, Raimundo (1997): Sociogénesis de una disciplina escolar: la Historia, Barcelona, Pomares-Corredor.

Cuesta, Raimundo (1999): La educación histórica del deseo. La didáctica de la crítica y el futuro del viaje a Fedicaria, Con-Ciencia Social. Anuario de didáctica de la geografía, la historia y otras ciencias sociales (Madrid), $\mathrm{n}^{\circ} 3$, pp. 70-97.

Cuesta, Raimundo (2007): Los deberes de la memoria en la educación, Barcelona, Octaedro.

Escolano, Agustín (2006): La modernización de la manualística escolar, en: VV.AA.: Historia ilustrada de la escuela en España. Dos siglos de perspectiva histórica, Madrid, Fundación Germán Sánchez Ruipérez, pp. 447-470.

Foucault, Michel (1996): Vigilar y castigar. Nacimiento de la prisión, Madrid, Siglo XXI.

Guillaumin, Colette (1992): Sexe, race et practique de pouvoir. L'idée de Nature, Paris, Éditions Côté Femmes.

Lave, Jean (1991): La cognición en la práctica, Barcelon, Paidos.

Lorente, Ángel (2001): Códigos profesionales y poderes ocultos en los institutos de Zaragoza, en: Mainer, J. (coord.): Discursos y prácticas para una didáctica crítica, Sevilla, Diada, pp. 177-196.

Lorente, Ángel (2006): Cultura docente y organización escolar en los institutos de secundaria, Profesorado. Revista de curriculum y formación del profesorado, 10, 2. Consultado en internet: 14-02-2014.

Nead, Lynda (1998): El desnudo femenino. Arte, obscenidad y sexualidad. Madrid, Tecnos.

Martín Criado, Enrique (2010): La escuela sin funciones. Crítica de la sociología de la educación crítica, Barcelona, Ediciòns Bellaterra. 
Merchán Iglesias, Francisco. J. (2005): Enseñanza, examen y control: Profesores y alumnos en la clase de Historia, Barcelona, Octaedro.

Milstein, Diana y Mendes, Héctor (1999): La escuela en el cuerpo: estudios sobre el orden escolar y la construcción social de los alumnos en escuelas primarias, Madrid, Miño y Dávila Editores.

Pérez-Guerrero, Vicente M. (2005): El cuerpo en la escuela. Una perspectiva de análisis sociogenética, Investigación en la escuela, $n^{\circ} 55$, pp. 103-113.

Pereyra, Miguel Á. (2002): La jornada escolar y su reforma en España: un marco de compresión, en: Pereyra, M. Á., González Faracao, J. C. y Coronel, J. M. (coords.) Infancia y escolarización en la modernidad tardía, Madrid, Akal, pp. 71-104.

Scott, Joan W. (1990): El género: útil para el análisis histórico, en: Amelang, J. y Nash, M. (eds.). Historia y género: las mujeres en la Europa moderna y contemporánea, Edicions Alfons el Magnanim, Institució Valencina d Estudis i Investigació, pp. 23-54.

Varela, Julia (1991): El cuerpo de la infancia. Elementos para una genealogía de la ortopedia pedagógica, en: VV.AA., Sociedad, cultura y educación. Homenaje a la memoria de Carlos Lerena Alesón, Madrid, Centro de Investigación y Documentación Educativa, Universidad Complutense de Madrid, pp. 229-247. 